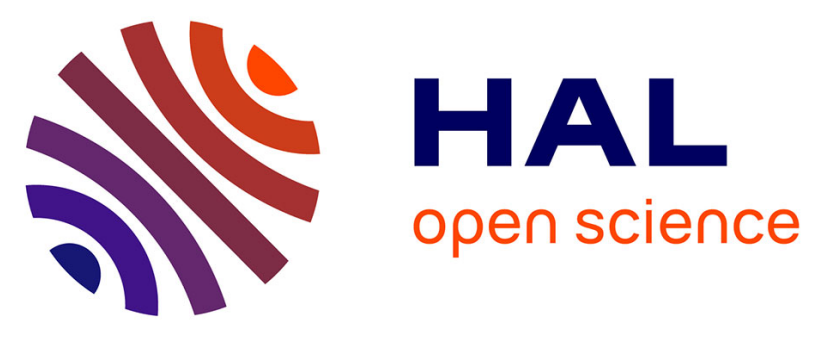

\title{
$\beta$-Cyclodextrin-Functionalized Chitosan/Alginate Compact Polyelectrolyte Complexes (CoPECs) as Functional Biomaterials with Anti-Inflammatory Properties
}

Alexandre Hardy, Cendrine Seguin, Anaïs Brion, Philippe Lavalle, Pierre

Schaaf, Sylvie Fournel, Line Bourel-Bonnet, Benoit Frisch, Marcella de Giorgi

\section{To cite this version:}

Alexandre Hardy, Cendrine Seguin, Anaïs Brion, Philippe Lavalle, Pierre Schaaf, et al.. $\beta$ Cyclodextrin-Functionalized Chitosan/Alginate Compact Polyelectrolyte Complexes (CoPECs) as Functional Biomaterials with Anti-Inflammatory Properties. ACS Applied Materials \& Interfaces, 2018, 10 (35), pp.29347-29356. 10.1021/acsami.8b09733 . hal-02185316

\section{HAL Id: hal-02185316 https://hal.science/hal-02185316}

Submitted on 10 Jan 2022

HAL is a multi-disciplinary open access archive for the deposit and dissemination of scientific research documents, whether they are published or not. The documents may come from teaching and research institutions in France or abroad, or from public or private research centers.
L'archive ouverte pluridisciplinaire HAL, est destinée au dépôt et à la diffusion de documents scientifiques de niveau recherche, publiés ou non, émanant des établissements d'enseignement et de recherche français ou étrangers, des laboratoires publics ou privés. 


\section{$\beta$-Cyclodextrin-Functionalized Chitosan/Alginate}

\section{Compact PolyElectrolyte Complexes (CoPECs) as}

\section{Functional Biomaterials with Anti-Inflammatory}

\section{Properties}

Alexandre Hardy,$^{\dagger}$ Cendrine Seguin, ${ }^{\dagger}$ Anaïs Brion,,$^{\dagger}$ Philippe Lavalle, ${ }^{\ddagger}$ Pierre Schaaf, ${ }^{\ddagger}$

Sylvie Fournel, ${ }^{\dagger}$ Line Bourel-Bonnet, ${ }^{\dagger}$ Benoit Frisch ${ }^{*}{ }^{\dagger}$ and Marcella De Giorgi ${ }^{*}{ }^{\dagger}{ }^{\dagger}$

${ }^{\dagger}$ Université de Strasbourg, CNRS, Laboratoire de Conception et Application de Molécules Bioactives UMR 7199, Faculté de Pharmacie, 74 route du Rhin, 67401 Illkirch Cedex, France

ثUniversité de Strasbourg, INSERM, Biomaterials and Bioengineering UMR 1121, Faculté de Chirurgie Dentaire de Strasbourg, Fédération de Médecine Translationnelle de Strasbourg, 11, Rue Humann, 67085 Strasbourg Cedex, France

KEYWORDS. Natural biomaterials, CoPECs, chitosan, alginate, cyclodextrins, antiinflammatory, drug carriers.

ABSTRACT. Nowadays, the need for therapeutic biomaterials displaying anti-inflammatory properties to fight against inflammation-related diseases is continuously increasing. Compact PolyElectrolyte Complexes (CoPECs) represent a new class of materials obtained by 
ultracentrifugation of a polyanion/polycation complexes suspension in the presence of salt. Here, a non-cytotoxic $\beta$-cyclodextrin-functionalized chitosan/alginate CoPEC was formulated, characterized and described as a promising drug carrier displaying an intrinsic anti-inflammatory property. This new material was successfully formed and due to the presence of cyclodextrins, it was able to trap and release hydrophobic drugs such as Piroxicam used as model drug. The intrinsic anti-inflammatory activity of this CoPEC was analyzed in vitro using murine macrophages in the presence of LipoPolySaccharide (LPS) endotoxin. In this model, it was shown that CoPEC inhibited LPS-induced TNF- $\alpha$ and NO release and moderated the differentiation of LPS-activated macrophages. Over time, this kind of bioactive biomaterial could constitute a new family of delivery systems and expand the list of therapeutic tools available to target inflammatory chronic diseases such as arthritis or Crohn's disease.

\section{INTRODUCTION}

Nowadays, the development of biomaterials such as nano and microparticles, beads, membranes or implants is of great importance in biomedical, biotechnological and pharmaceutical fields. Biomaterials features, along with bio-industrial requirements, have progressively evolved from bio-inertia to biocompatibility and biodegradability, to finally target a fully controlled bioactivity. To date the use of those therapeutic biomaterials is envisaged for the treatment of different diseases as for example inflammatory chronic diseases. ${ }^{1}$

Inflammation is part of the innate immune response involved in the fight against pathogens and cancer. Inflammation is physiologically induced by pathogen-associated molecular pattern (PAMP) or damage-associated molecular pattern (DAMP). For example, 
LipoPolySaccharide (LPS), as part of Gram-negative bacteria cell wall (endotoxin), is a PAMP known to induce inflammation. Inflammation is physiologically highly regulated. However, in some cases it becomes chronic and is involved in the development of many severe diseases such as cancer, rheumatoid arthritis or Crohn's disease. Numerous antiinflammatory biomaterials have been developed and most of them display this activity by releasing an anti-inflammatory active substance incorporated in their structure..$^{2,3,4,5,6}$ To date, only few biomaterials showing intrinsic anti-inflammatory properties have been described, among them one can enumerate silver, ${ }^{7,8,9}$ cerium oxide nanoparticles ${ }^{10,11}$ and some hydrogels made of $N$-acryloyl glycinamide ${ }^{12}$ or hyaluronic acid..$^{13}$

When considering further pharmacological development, fully natural polymers or synthetic ones possessing hydrolysable bonds and/or recyclable units are generally preferred for new biomaterials.

Chitosan is a natural cationic aminopolysaccharide obtained from the $N$-deacetylation of chitin, which is a structural constituent of crustacean shells. It is biocompatible, biodegradable, nontoxic and exhibits antimicrobial activity against bacteria and fungi. ${ }^{14}$ Alginate is a natural anionic and hydrophilic polysaccharide isolated from marine brown algae species or produced by bacteria..$^{15}$ It is biocompatible and has a low toxicity as well as a relatively low cost.

Due to their respective remarkable biological properties, numerous works related to the association of these two polyelectrolytes have already been conducted and have led to a large variety of biomaterials. Association of these two components find applications as membranes for soft tissue engineering, ${ }^{16,17}$ as hydrogels for tissue regeneration, ${ }^{18}$ as nanoparticles ${ }^{19,20,21}$ or micro and nanocapsules ${ }^{22,23}$ for drug carrying or dying, as polymer networks for cartilage regeneration ${ }^{24}$ or as fibers for other applications. ${ }^{25}$ These biomaterials show different features 
depending on polymer concentrations and/or formulation conditions such as $\mathrm{pH}$, ionic strength and temperature.

Recently, Schlenoff and coworkers first described so-called Compact PolyElectrolyte Complexes (CoPECs) obtained by mixing two oppositely charged synthetic polyelectrolytes, such as poly(diallyldimethylammonium) (PDADMA) and poly(styrene sulfonate) (PSS), in the presence of salt and then compacting the resulting complexes by ultracentrifugation or extrusion. These innovative materials were described as saloplastic, as they show a plastic behavior thanks to the presence of salt that plays the role of plasticizer. ${ }^{26,27}$ Then, as part of our research in the field of drug delivery, Reisch et al. worked on complexes of poly(acrylic acid) (PAA) and poly(allylamine hydrochloride) (PAH) and showed that these materials possess remarkable self-healing and stretching properties. ${ }^{28,29}$ Moreover, Tirado et al. also demonstrated that these materials have the interesting properties to immobilize, protect and enhance the activity of enzymes incorporated inside their structure..$^{30}$

In a recent work, Phoeung et al. found that by finely tuning the experimental conditions one can process chitosan/alginate based CoPECs which are anti-adhesive against cells and non pro-inflammatory materials. ${ }^{31}$ As these new chitosan/alginate-based CoPECs do not have the ability to carry drugs and especially hydrophobic drugs due to their hydrophilic properties, the first aim of the present work was to modify natural chitosan and alginate to develop functionalized chitosan/alginate CoPECs to further give them the ability to carry and release drugs. For that purpose, we envisaged to functionalize these two polysaccharides with a cyclodextrin ring able to create host-guest interactions with hydrophobic drugs.

Cyclodextrins (CDs) are cyclic oligosaccharides obtained by enzymatic degradation of starch, composed of $\alpha-(1,4)-D$-glucopyranose units. The three common natural $\alpha-, \beta-$ and $\gamma$ cyclodextrins are constituted of six, seven and eight glucose residues, respectively. Usually 
presented as a 3D-truncated cone, CDs are hydrophilic on their outer surface due to the numerous hydroxyl groups but their inner cavity is essentially hydrophobic. CDs have therefore the ability to host lipophilic molecules while being soluble in water. Among the three common cyclodextrins and given the ideal size of its cavity (internal diameter of 6.0 to $6.5 \AA$ ), the $\beta-\mathrm{CD}$ (Figure 1) is particularly well-adapted to form host-guest inclusion complexes with a wide variety of molecules containing a hydrophobic moiety..$^{32,33,34}$

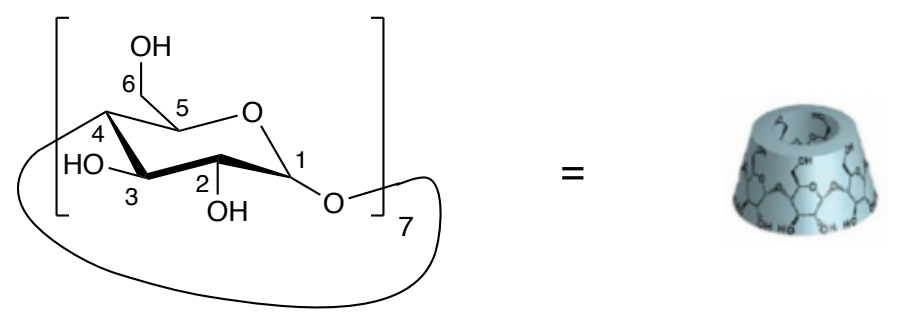

Figure 1. Structure of $\beta$-cyclodextrin.

In this original work, $\beta$-cyclodextrin-functionalized chitosan/alginate CoPEC was designed to be further used as potential new carrier for drug delivery. The newly functionalized CoPEC was thoroughly characterized and its intrinsic anti-inflammatory properties were fully assessed through in vitro biological assays.

\section{RESULTS AND DISCUSSION}

\subsection{Synthesis and characterization of $\beta$-cyclodextrin functionalized chitosan}

Different methods to obtain functionalized $\beta$-cyclodextrins (amino, formyl, carboxy, halogeno-CDs) have already been reported in the literature. ${ }^{35}$ In this work, we were interested in the functionalization of $\beta$-cyclodextrin on its primary hydroxyl group by a leaving group 
that could be further displaced by nucleophiles to synthesize useful derivatives. For that purpose, 6-OTs- $\beta$ CD 1 was synthesized from commercially available $\beta C D$ (Scheme 1)
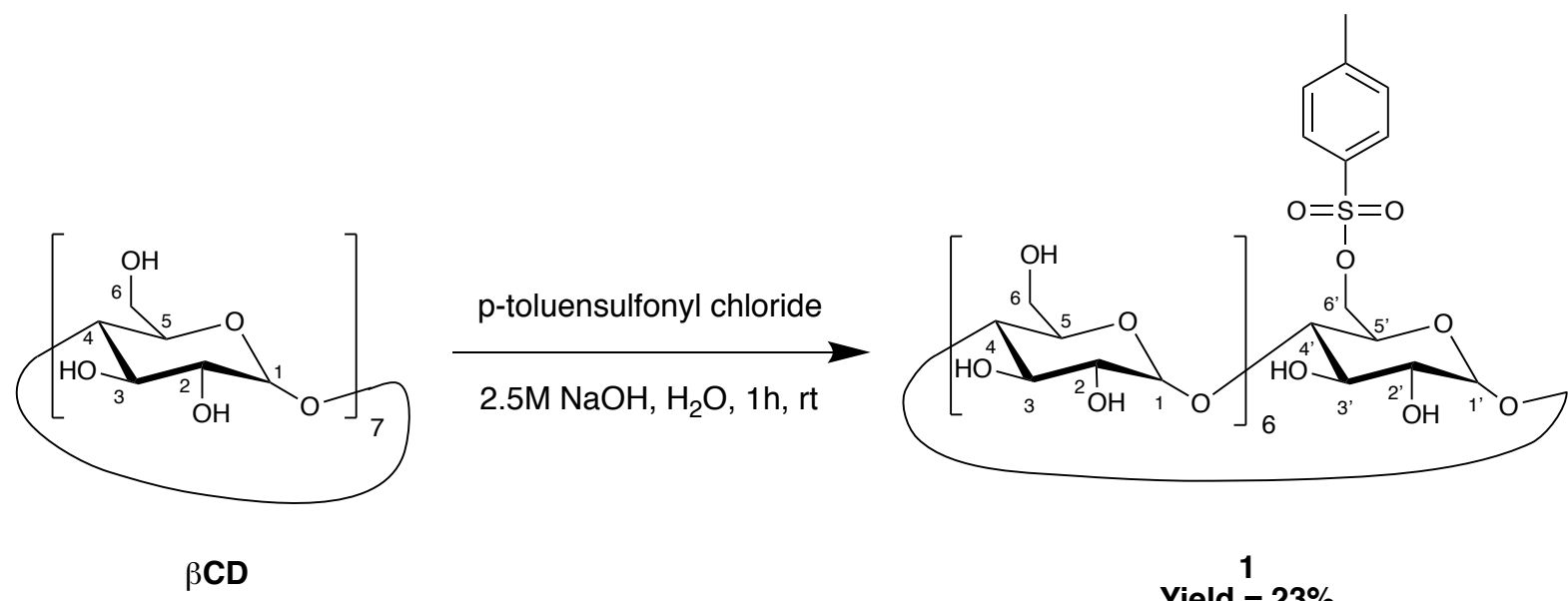

Yield $\stackrel{1}{=} 23 \%$

Scheme 1. Synthesis of 6-OTs- $\beta$ CD (1)

The monotosylation of $\beta$-cyclodextrin on its primary hydroxyl group has been extensively studied exploiting either aqueous or organic solvents polarity. Pyridine is a solvent reputed optimal for a selective monotosylation on the 6-OH-position of $\beta C D$. It generally results in good conversion yields, but its removal is never complete leading to sub-optimal subsequent coupling reactions with polysaccharides. In the present work the monotosylation reaction was performed accordingly to Tripodo's method, ${ }^{36}$ in an aqueous $\mathrm{NaOH}$ solution and the purification of the crude product was further performed with a cation-exchange resin. The overall yield of this reaction (23\%) and the purity of the product (99.9\%) were in accordance with the literature (respectively $35 \%$ and $>98 \%$ ). The ${ }^{1} \mathrm{H}$ NMR spectrum was also in accordance with the expected product 1 , with characteristic signals of $\beta$-cyclodextrin and one tosyl group. The resulting 6-OTs- $\beta C D 1$ was further used in reactions with chitosan (Scheme 2). 
Gonil et al. described a nucleophilic substitution between $-\mathrm{NH}_{2}$ groups of chitosan and 6OTs- $\beta C D$ under acidic conditions (acetic acid $1 \% \mathrm{v} / \mathrm{v}$ in water), the tosyl being a good leaving group (Scheme 2). ${ }^{37}$
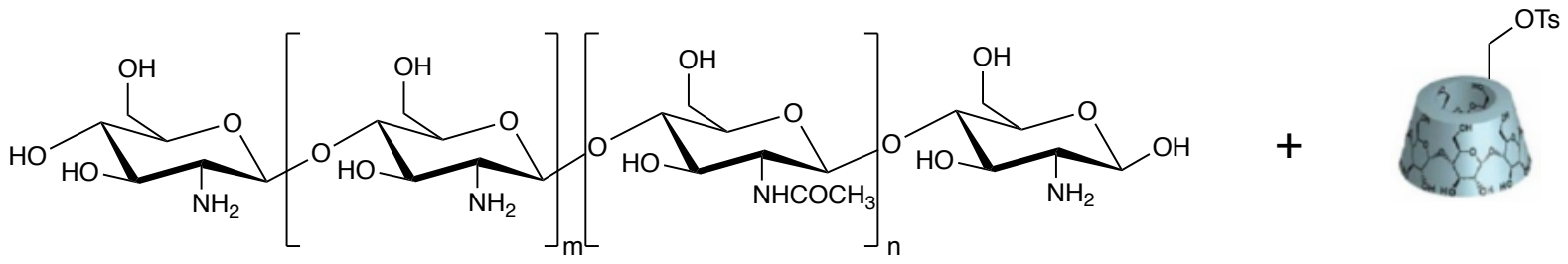

Chitosan

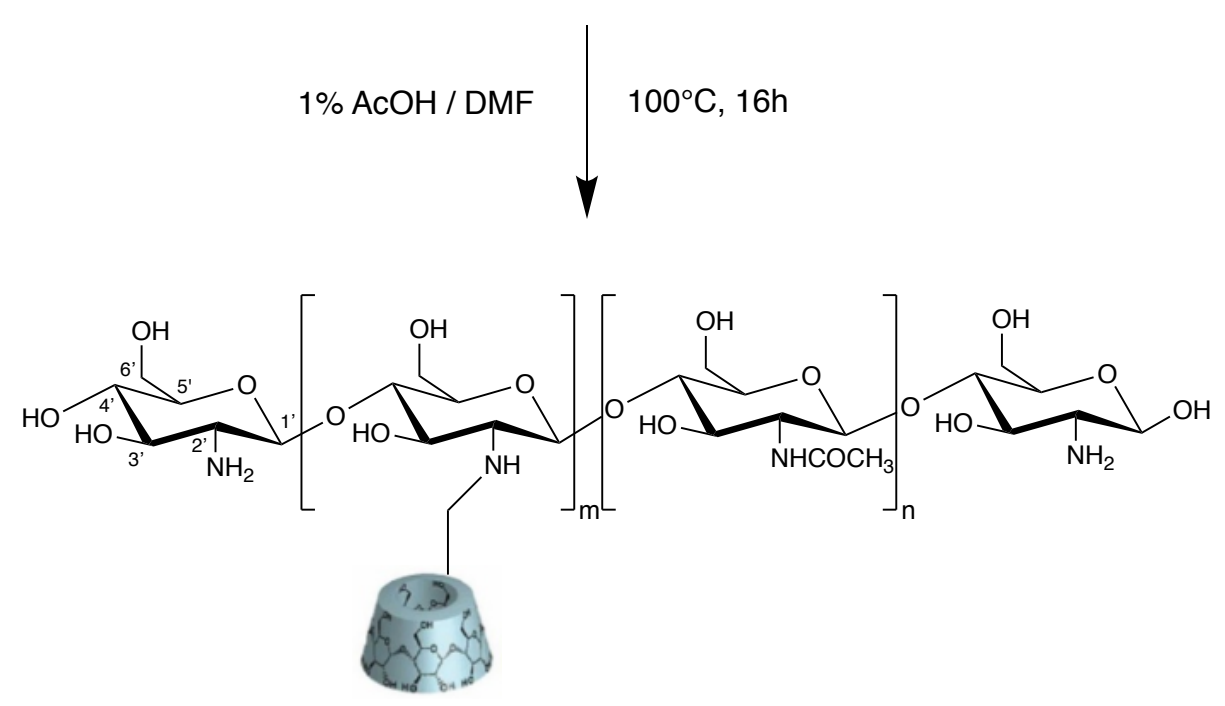

2

Scheme 2. Synthesis of $\beta C D$-chitosan (2).

${ }^{1} \mathrm{H}$ NMR spectroscopy was used to assess the substitution degree (DS) of the functionalized chitosan. The integration value of the $\mathrm{H} 1$ anomeric proton of cyclodextrin signal at $\delta 4.98$ ppm was compared to that of chitosan $\mathrm{H} 2$ ' protons at $\delta 2.89 \mathrm{ppm}$ through the following equation:

$$
D S(\%)=\frac{H 1 C D / 7}{H 2^{\prime} \text { Chitosan }}
$$


We found a DS of $25 \%$.

\subsection{Preparation of CoPECs}

Recently two processing methodologies combining polysaccharides and/or synthetic polyelectrolytes showed the possibility to obtain Compact PolyElectrolyte Complexes either by ultracentrifugation/extrusion ${ }^{27}$ or by evaporation ${ }^{17}$ in the presence of salt. Here we prepared CoPECs by the ultracentrifugation method. Alginate is known to form good complexes between its carboxylic groups $(-\mathrm{COOH})$ and primary amino groups of the natural polysaccharide chitosan $\left(-\mathrm{NH}_{2}\right)$ through the $\mathrm{COO}^{-} / \mathrm{NH}_{3}{ }^{+}$ion pair. We chose this binary system as an original natural-based CoPECs formulation. In a recent work ${ }^{31}$ we identified suitable assembly conditions leading to handy and macroscopically homogeneous biomaterials. Besides the types of polyelectrolytes and their relative quantity, influence of $\mathrm{pH}$ and salt concentration on the macroscopic properties of COPEC were studied and optimal formulation conditions were determined.

In the present work, we functionalized chitosan and alginate with $\beta$-cyclodextrin and we first formulated three new CoPECs, i. e. $\beta C D$-chitosan/alginate ( $\beta C D-C h i / A l g)$, chitosan/ $\beta C D$ alginate and $\beta C D$-chitosan/ $\beta C D$-alginate CoPECs. Early in vitro studies showed a proinflammatory activity of the chitosan/ $\beta \mathrm{CD}$-alginate and $\beta \mathrm{CD}$-chitosan/ $\beta \mathrm{CD}$-alginate $\mathrm{CoPECs}$ (Supporting Information, Figures S1, S2 and S3) so that we only focus here on the $\beta C D$ chitosan/alginate CoPEC.

The functionalization of chitosan with cyclodextrins $(\mathrm{DS}=25 \%)$ led to a decrease of the number of amino groups available for the complexation with alginate. Thus, for the formulation of $\beta \mathrm{CD}$-chitosan/alginate $\mathrm{CoPEC}$, we increased by around $25 \%$ the number of 
chitosan sugar units to reach the same number of ionic groups as in the case of the CoPEC made from unmodified chitosan.

The ionic strength of the medium influences the plasticity of the material during the complexation and the ultracentrifugation processes. Indeed, low salt concentrations lead to soft biomaterials uneasy to handle, while high salt concentrations lead to more compact materials. Based on our previous results, a $1 \mathrm{M} \mathrm{NaBr}$ concentration was chosen for the formulation of all the $\beta C D$ functionalized chitosan/alginate CoPECs. ${ }^{31}$

Finally, the ultracentrifugation was performed at $308,000 \mathrm{~g}$ and $23^{\circ} \mathrm{C}$ for $12 \mathrm{~h} \cdot{ }^{31}$ All these conditions led to a homogenous and easy to handle material (Figure 2a).
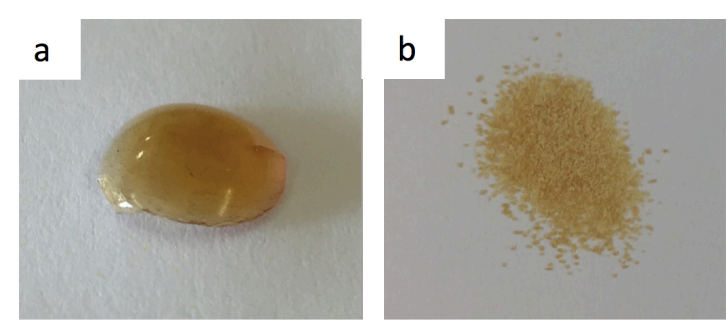

Figure 2. a) Physical aspect of $\beta \mathrm{CD}-\mathrm{Chi} / \mathrm{Alg}$ CoPEC sample obtained after ultracentrifugation: $[\mathrm{NaBr}]=1 \mathrm{M}$; [Polysaccharides $]=1.25 \mathrm{mg} / \mathrm{mL}$ and ultracentrifugation speed $=308,000 \mathrm{~g}$; b) $\beta \mathrm{CD}-\mathrm{Chi} / \mathrm{Alg}$ CoPEC microparticles $(\leq 300 \mu \mathrm{m})$ obtained after crushing and sieving steps on freeze-dried CoPEC.

These materials could easily be freeze-dried and reshaped as microparticles by crushing/sieving steps, affording homogeneous CoPECs powders suitable for in vitro assays (Figure $2 \mathrm{~b}$ ). Here, the use of microparticles of diameter smaller than $300 \mu \mathrm{m}$ permits to obtain a dose-response relationship during in vitro assays.

\subsection{Surface and inner microstructures observations}


Next we compared the structure of Chi/Alg and $\beta$ CD-Chi/Alg CoPECs before crushing (that is to say immediately after ultracentrifugation and freeze-drying). We used Scanning Electron Microscopy for that purpose. As shown on Figure 3, the different microstructures were not porous but very homogeneous. Moreover, the general aspect of Chi/Alg (a and b) and $\beta C D-$ Chi/Alg (c and d) CoPECs was similar.
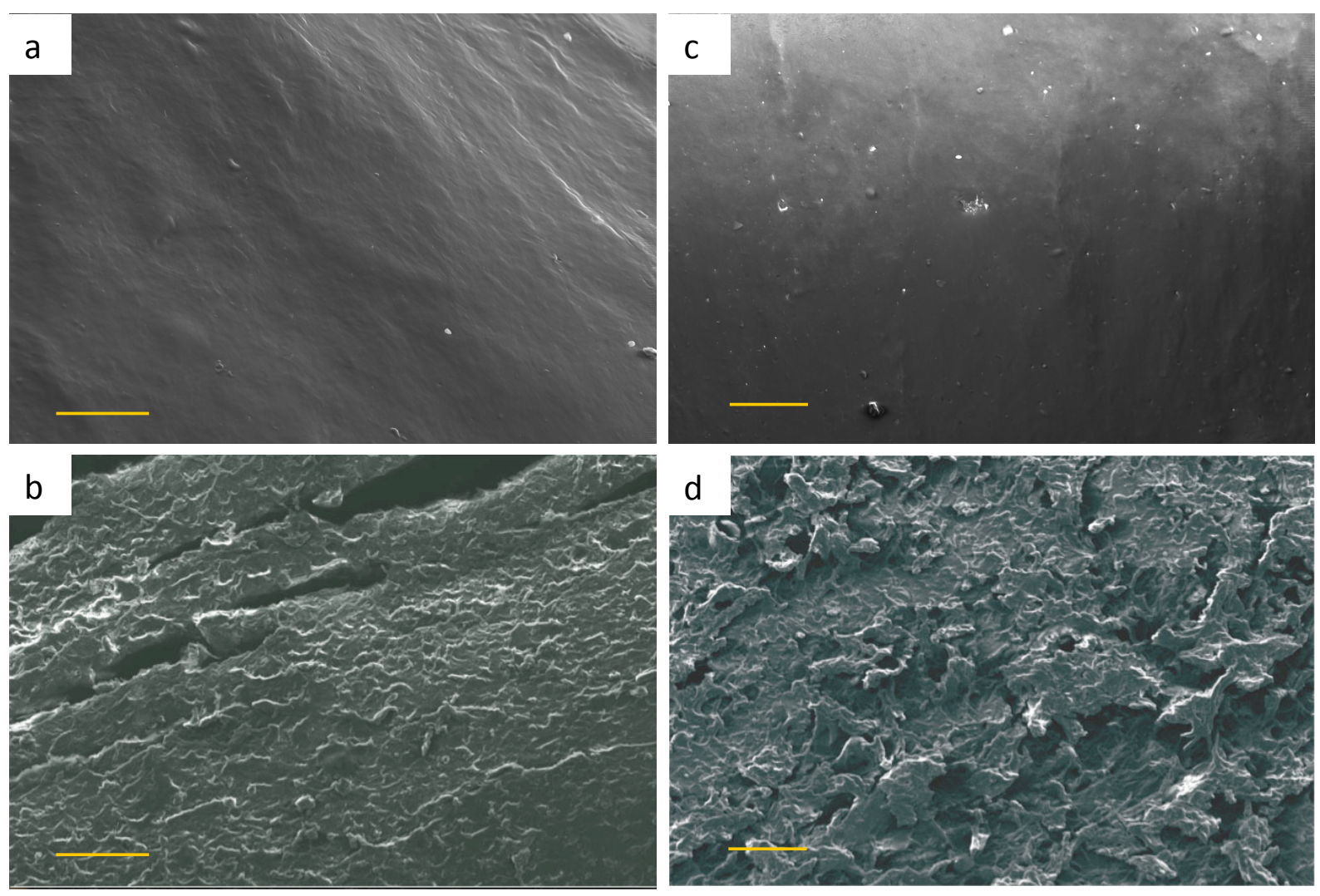

Figure 3. SEM images of the homogeneous and non porous surface and interior of Chi/Alg (a and b, respectively) and $\beta$ CD-Chi/Alg (c and d, respectively) CoPECs (yellow bar $=100 \mu \mathrm{m}$ ).

Therefore, it seems that the chemical modification of the CoPEC by $\beta$-cyclodextrin has no great impact on the microstructure of the final material.

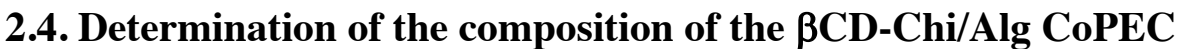


During the polyelectrolytes complexe formulation, all the introduced molecules are not necessarily complexed and some free molecules may remain in the supernatant. Thus, in order to evaluate the ratio between the two constituents of the material ( $\beta \mathrm{CD}$-chitosan and alginate), alginate was labeled on its carboxylate groups with rhodamine B isothiocyanate and titrated by UV-Vis spectrophotometry. The substitution degree of the labeled polymer was $0.7 \%$, which was enough to detect the alginate and sufficiently low to keep the molar mass of the polymer and its overall charge unchanged.

According to the UV-Vis spectrophotometry measurements obtained with the supernatant before ultracentrifugation, only $0.2 \mathrm{mg}$ out of $10.3 \mathrm{mg}$ of alginate were found there, which means that more than $98 \%$ of alginate was complexed into the final material. That data allowed us to deduce the amount of $\beta C D$-chitosan in the final CoPEC. On a dry $\beta C D$-Chi/Alg CoPEC sample of $18.4 \mathrm{mg}, 8.3 \mathrm{mg}$ of $\beta C D$-chitosan and $10.1 \mathrm{mg}$ of alginate were found corresponding to $0.051 \mathrm{mmol}$ of $\left(\mathrm{COO}^{-}+\mathrm{COOH}\right)$ from alginate units and $0.012 \mathrm{mmol}$ of $\left(\mathrm{NH}_{3}{ }^{+}+\mathrm{NH}_{2}\right)$ from $\beta \mathrm{CD}$-chitosan units. The molar ratio $\left(\mathrm{COO}^{-}+\mathrm{COOH}\right) /\left(\mathrm{NH}_{3}{ }^{+}+\mathrm{NH}_{2}\right)$ is thus of 1:0.24. This ratio, with an excess of alginate, is probably due to the steric hindering coming from the cyclodextrins grafted onto chitosan, leading to a need for more alginate moieties to reach the different cationic groups of $\beta C D$-chitosan.

\subsection{Inclusion of Piroxicam in chitosan/alginate and $\beta C D$-chitosan/alginate CoPECs}

In order to evaluate the ability of our functionalized CoPEC to trap and deliver hydrophobic drugs, a model drug, Piroxicam, was included into chitosan/alginate and $\beta C D$ chitosan/alginate CoPECs. The inclusion was performed in methanol, this solvent being optimal as its modest polarity permits the solubilization of Piroxicam and forces the hydrophobic moieties to reach the cyclodextrin cavities. Included Piroxicam was then 
extracted from the CoPECs using dichloromethane, a strongly hydrophobic solvent. The extracted Piroxicam was quantified by UV-Vis spectrophotometry and, from the same amount of chitosan/alginate and $\beta C D$-chitosan/alginate CoPECs $(10 \mathrm{mg})$, we quantified 1.24 and 2.99 $\mu \mathrm{mol}$ of Piroxicam, respectively. Thus, the presence of $\beta \mathrm{CD}$ in the CoPEC allowed more than a doubling of the quantity of Piroxicam included.

After performing characterizations of this new functional material and verifying its ability to trap and release a hydrophobic model drug, we conducted in vitro biological assays to evaluate its potential anti-inflammatory activity.

\subsection{Evaluation of the anti-inflammatory activity of CoPECs}

The in vitro evaluation of the anti-inflammatory properties of a material is usually conducted using macrophages that can be activated by chemical compounds to mimic inflammation. The anti-inflammatory activity is then estimated by assessing the amount of various inflammation mediators produced by the cells such as nitric oxide (NO) or pro-inflammatory cytokines. Moreover, inflammation induces differentiation of macrophages that results in the decrease of proliferation as well as differentiation/activation marker expression.

In our study, RAW 264.7 mouse macrophages were activated by LPS, a well-known endotoxin described as an inflammation inducer. The viability of those macrophages in the presence of CoPECs was assessed as well as the production of NO and TNF- $\alpha$ proinflammatory cytokines in cell supernatants. The expression of Ki-67 and CD40 was followed as proliferation and activation markers, respectively.

Flow cytometry analyses using a Fixable Viability Dye (FVD) demonstrated that chitosan/alginate and $\beta C D$-chitosan/alginate CoPECs were not cytotoxic, both on LPS- 
activated and non-activated cells (Figure 4). Indeed the percentage of viable cells is similar when cells are not treated $([\mathrm{CoPEC}]=0 \mathrm{mg} / \mathrm{mL})$ and when they are treated with CoPECs.

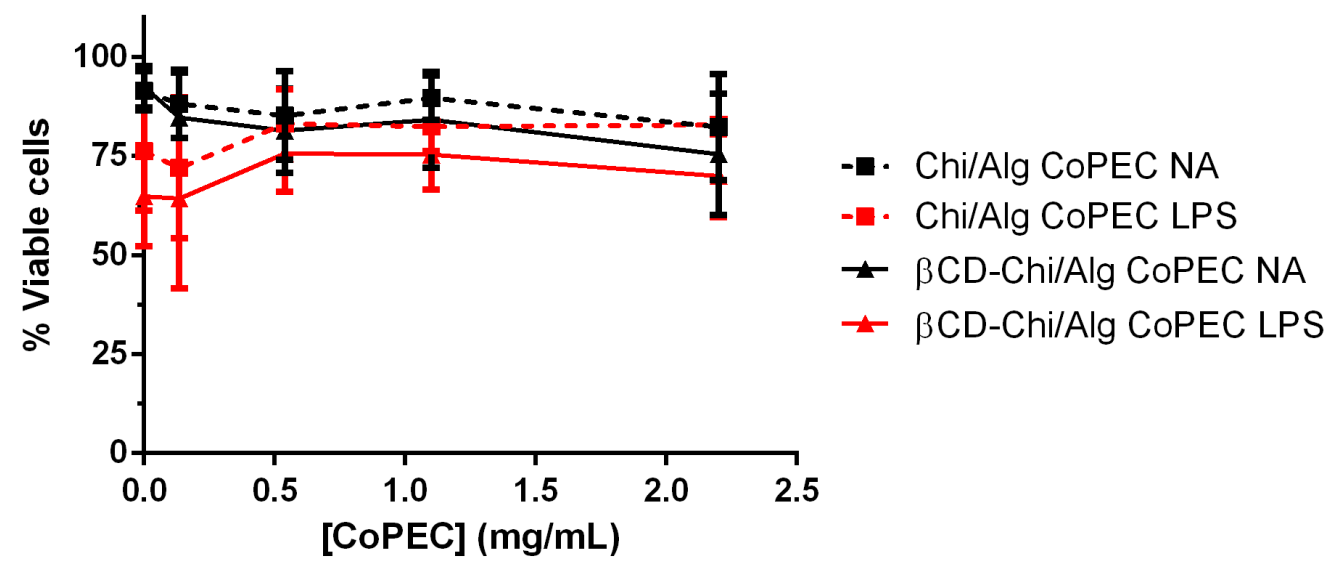

Figure 4. CoPECs functionalized or not by $\beta$-cyclodextrins are non-cytotoxic. Raw cells were preincubated $24 \mathrm{~h}$ with CoPECs before $24 \mathrm{~h}$ activation with $50 \mathrm{ng} / \mathrm{mL}$ LPS. Viability was assessed by cytometry with a FVD labeling $(n=3)$. NA = Non-activated cells and LPS = LPSactivated cells.

To analyze the effect of CoPECs devoid of active substance on NO release and proinflammatory cytokine production, macrophages were incubated with CoPECs for 24 hours and then activated by LPS for $24 \mathrm{~h}$. As expected, LPS induced the production of NO (Figure $5 a)$ and TNF- $\alpha$ (Figure $5 b$ ). The CoPECs containing or not $\beta C D$ caused a decrease of NO and TNF- $\alpha$ detected in cell supernatants. Interestingly, although these decreased NO and TNF- $\alpha$ levels were observed for both CoPECs (i. e. with or without cyclodextrin), it was much more noticeable in the case of the cyclodextrin-containing one (solid red line). Moreover, one can notice that in the case of TNF- $\alpha$, this cytokine is almost absent in the supernatants after treatment by the $\beta C D$-chitosan/alginate CoPEC. 
a.

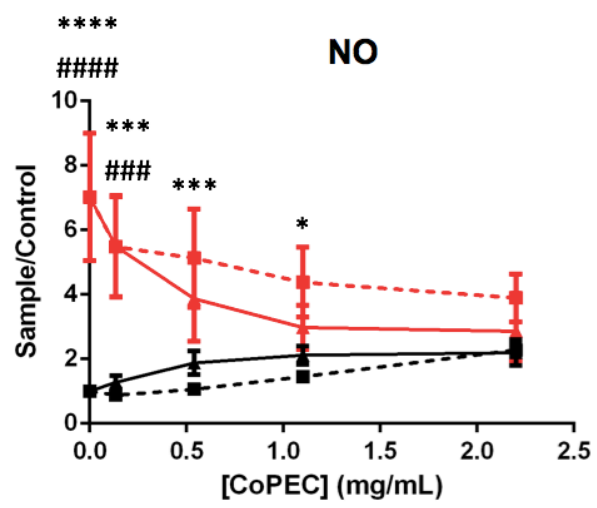

b.

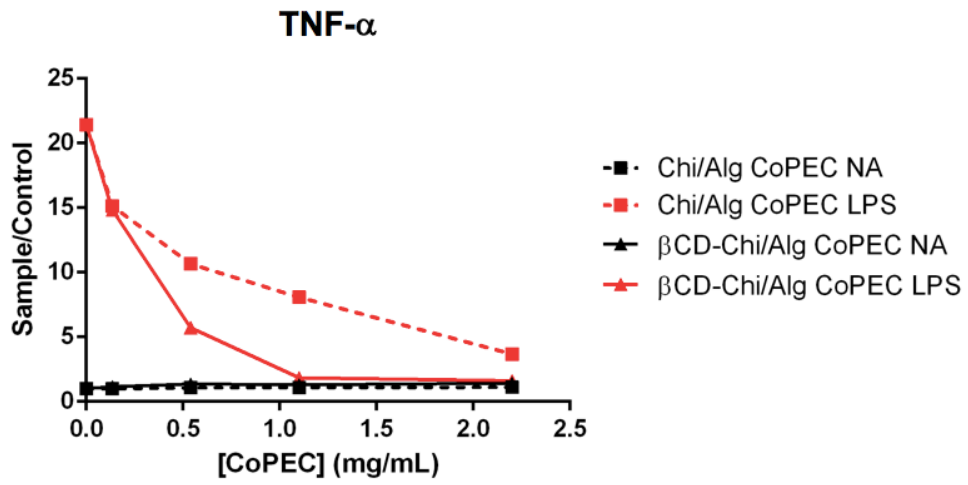

Figure 5. CoPECs functionalized or not by $\beta$-cyclodextrins decrease NO and TNF- $\alpha$ production by activated cells in a dose dependent manner. Raw cells were activated by 50ng/mL LPS 24h after incubation with CoPECs. Cell supernatants were collected 24h after activation. Data are presented as a ratio between the different samples and the referent untreated RAW cell supernatant (no CoPEC, no LPS). NO production (a) was assessed by Griess test $(\mathrm{n}=3)$ and TNF- $\alpha$ production (b) was estimated by ELISA test ( $\mathrm{n}=1$ representative of 3 experiments). NA $=$ Non-activated cells and LPS $=$ LPS-activated cells. $* * * *, * * *$ and $*$ $=$ p-value $<0.0001,<0.001$ and $<0.05$ respectively, difference between Chi/Alg CoPEC NA and Chi/Alg CoPEC LPS. \#\#\#\# and \#\#\# = p-value $<0.0001$ and $<0.001$ respectively, difference between $\beta$ CD-Chi/Alg CoPEC NA and $\beta$ CD-Chi/Alg CoPEC LPS.

NO and TNF- $\alpha$ determinations were also conducted with the Piroxicam-containing $\beta C D$ chitosan/alginate CoPEC (Supporting Information, Figures S4 and S5). In these experiments, the different functionalized CoPEC concentrations corresponded to Piroxicam concentrations ranging from around 25 to $200 \mu \mathrm{g} / \mathrm{mL}$. From these experiments it can be noticed that the Piroxicam-containing CoPEC induces a decrease of NO and TNF- $\alpha$ production by activated macrophages. However, the effect of CoPEC was not significantly better than that of the CoPEC devoid of Piroxicam. This could be explained by the low quantity of Piroxicam available in this case. Indeed, in order to obtain a significant anti-inflammatory effect due to 
Piroxicam alone, it is necessary to have at least $300 \mathrm{nmol}$ of Piroxicam/mL as described by Chiong et $a l .{ }^{38}$ In our work, even if the cyclodextrins are saturated by Piroxicam, the concentration in Piroxicam is pretty low in the samples $(62 \mathrm{nmol} / \mathrm{mL}$ for the first one $)$ and the effect of CoPEC alone is so important that the effect of Piroxicam is completely masked by the material (Supporting Information, S8). Hereinafter and for that reason, we focused on the CoPEC without Piroxicam for further studies.

To ensure that the lowered NO and TNF- $\alpha$ levels detected in cell supernatants were not due to any trapping of LPS and TNF- $\alpha$ in the materials and in particular into the cyclodextrins, two complementary experiments were conducted. In a first experiment, LPS was incubated with $\beta C D$-chitosan/alginate CoPEC for $24 \mathrm{~h}$, and then supernatants were incubated with macrophages. Here, we can observe that after being in contact with CoPEC, LPS induces a NO production from macrophages comparable to that induced by fresh LPS (+ Control) (Figure 6).

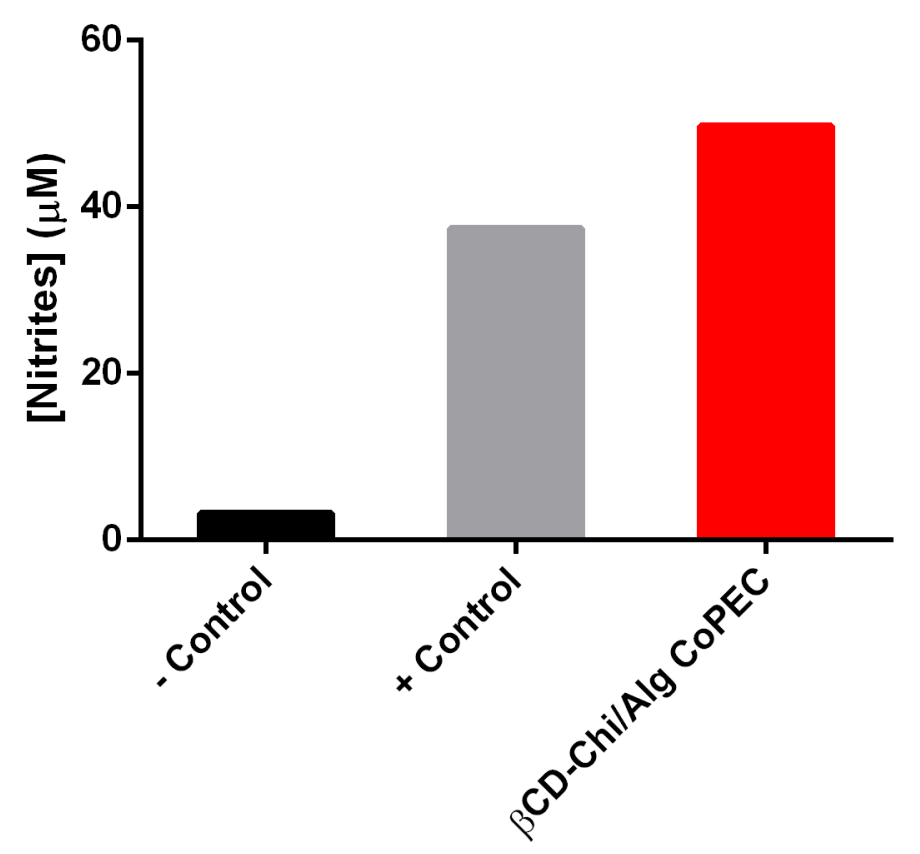


Figure 6. $\beta C D-C h i / A l g$ CoPEC does not trap LPS. LPS was incubated with CoPEC during 24h. Filtered CoPEC supernatant was then placed onto macrophages. 24h later, supernatant was collected. NO production was assessed by Griess test $(n=1)$. - Control corresponds to the NO production of non-activated macrophages and + Control corresponds to the NO production induced by the addition of fresh LPS onto macrophages.

In a second experiment, TNF- $\alpha$ was incubated with $\beta C D$-chitosan/alginate CoPEC for $24 \mathrm{~h}$ and was then quantified by ELISA. In this experiment, similar levels of TNF- $\alpha$ were detected both in the cases when this cytokine was incubated with CoPEC or not (Control) (Figure 7).

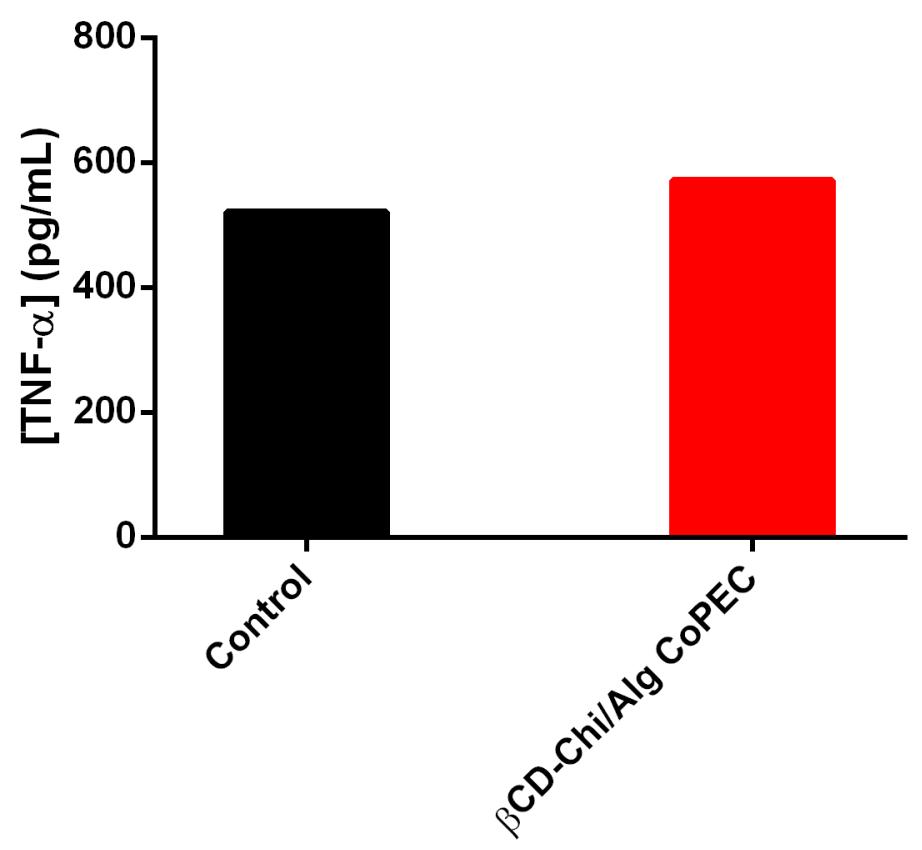

Figure 7. $\beta C D-C h i / A l g$ CoPEC does not trap TNF- $\alpha$. The CoPEC supernatant was collected $24 \mathrm{~h}$ after addition of TNF- $\alpha$. TNF- $\alpha$ content in supernatant was quantified by ELISA test ( $\mathrm{n}$ $=1$ ). The control corresponds to TNF- $\alpha$ in culture medium without any contact with CoPEC. 
From these two experiments, it can be concluded that the above mentioned inhibitions are not due to any trapping of LPS or TNF- $\alpha$ into the CoPECs. Thus, we can affirm that our CoPECs inhibit NO and TNF- $\alpha$ productions by activated macrophages, which is an evidence of the intrinsic anti-inflammatory action of our materials.

To confirm the intrinsic anti-inflammatory activity of $\beta \mathrm{CD}$-Chi/Alg CoPECs, the differentiation state of activated macrophages was evaluated by following proliferation using Ki-67 marker and following activation using CD40 marker. As expected, Figure 8 shows that macrophages stop proliferating (Figure 8a) and express the activation CD40 marker (Figure 8b) when activated by LPS. However, in the presence of CoPECs functionalized or not, proliferation is restored and CD40 expression is decreased, showing an inhibition of macrophage differentiation, so confirming the inhibition of the inflammation.

a.

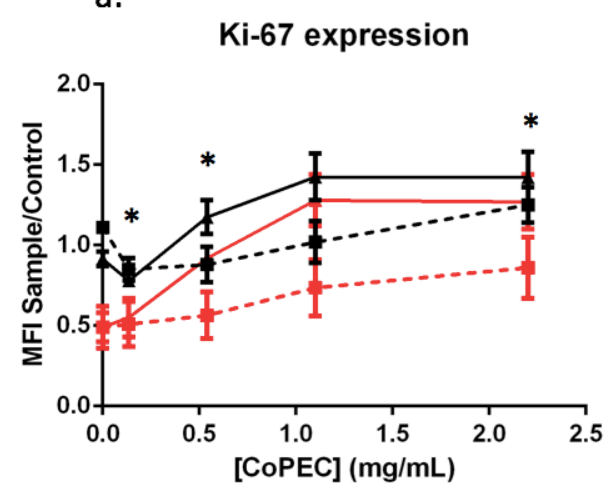

b.

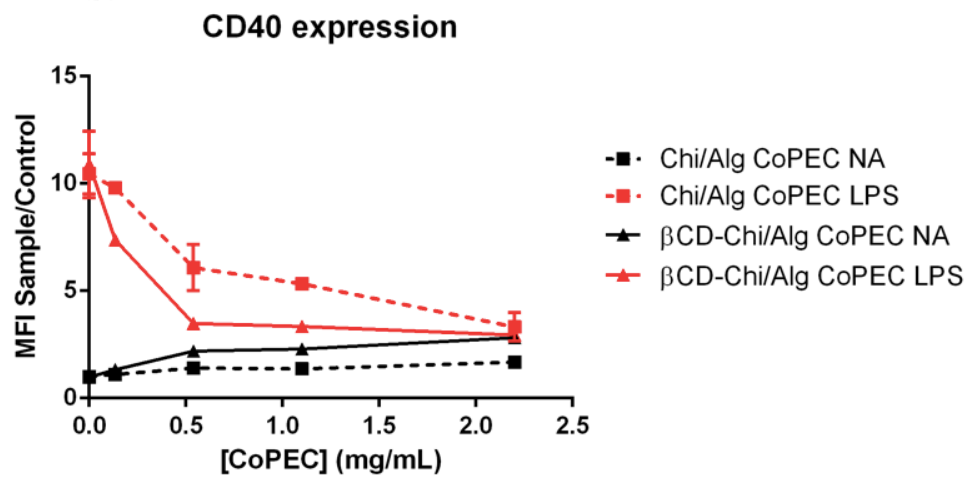

Figure 8. CoPECs functionalized or not restore cell proliferation and decrease LPS-induced cell activation. Raw cells were activated by LPS $24 \mathrm{~h}$ after incubation with CoPECs. $24 \mathrm{~h}$ after activation, cells were collected and cell proliferation and activation were estimated by cytometry with (a) Ki-67 (n=2) and (b) CD40 labeling $(n=2)$, respectively. Data are represented as a Median Fluorescent Intensity (MFI) ratio between sample and untreated RAW cells (no CoPEC, no LPS). NA = Non-activated cells and LPS = LPS-activated cells. * $=$ p-value $<0.05$, difference between Chi/Alg CoPEC NA and Chi/Alg CoPEC LPS. 
All together, these results show that our CoPECs have high intrinsic anti-inflammatory properties.

To better understand the biological activity of the materials, some in vitro evaluations have been conducted on the polyelectrolytes used for CoPEC formulation. In particular, the influence of alginate, chitosan and $\beta C D$-chitosan on the NO production by LPS-activated macrophages has been studied (Supporting Information, Figure S6). From these experiments, it can be concluded that the anti-inflammatory activity of CoPECs most probably comes from chitosan and $\beta C D$-chitosan as these two polyelectrolytes induce a lowering of NO production by activated cells. Our results seem to corroborate those obtained by Yoon et al..$^{39}$ and Zhu et $a l .{ }^{40}$ on chitosan oligosaccharides.

Thus, in this work, we have developed a saloplastic biomaterial made of $\beta$-cyclodextrinfunctionalized chitosan and alginate that preserves the anti-inflammatory activity of chitosan and that is able to contain and release hydrophobic drugs forming an inclusion complex with $\beta$-cyclodextrin. Compared to the unmodified chitosan/alginate CoPEC, we have detected a slightly increased anti-inflammatory activity of the $\beta$-cyclodextrin-functionalized material. Two hypothesis can be formulated to justify this effect: i) the modification of the tridimensional arrangement of the polyelectrolyte chains and ii) the modification of physicochemical properties (decrease of total positive charges number and enhanced solubility for example) of chitosan due to the presence of $\beta$-cyclodextrin. Therefore, we could consider that this new functionalized CoPEC has a very high potential as bioactive material that could find applications in implantable devices.

\section{CONCLUSIONS}


In the present work, the recently described chitosan/alginate CoPEC was functionalized with $\beta$-cyclodextrin. This modification led to a $\beta$-cyclodextrin-chitosan/alginate CoPEC, a new material that was characterized for its composition and microstructure. The ability of this new material to carry Piroxicam drug was demonstrated. Through in vitro experiments with an inflammation model (activated macrophages), this new functionalized CoPEC was demonstrated to be non-cytotoxic, to inhibit NO and pro-inflammatory cytokine TNF$\alpha$ production as well as to decrease LPS-induced differentiation. These are highly reliable proofs that this new biomaterial exhibits intrinsic anti-inflammatory activities. Moreover, these intrinsic anti-inflammatory activities of the CoPEC were so important that the presence of the anti-inflammatory Piroxicam could not enhanced its efficacy.

Next stage will be to include an active pharmaceutical ingredient devoid of anti-inflammatory activity (antibiotics or anticancer drug for example) into this $\beta$-cyclodextrin-chitosan/alginate CoPEC to evaluate its ability to carry and release such a molecule. Over time, this kind of biomaterial could constitute a new standard in the field of combination therapy with an intrinsic anti-inflammatory activity and an additional therapeutic effect provided by an extra active molecule included in the CoPEC.

\section{EXPERIMENTAL SECTION}

\subsection{Materials}

\section{1. 1. Chemical reagents and equipment}

Chitosan (average molecular weight 250,000; viscosity 30-100 cP; deacetylation degree > 90\%) was obtained from Glentham Life Sciences (Corsham, UK). Alginic acid sodium salt 
(average molecular weight 155,000 ; viscosity $15-20 \mathrm{cP} ; 1 \%$ in water), rhodamine $\mathrm{B}$ isothiocyanate, mixed isomers and acetic acid were obtained from Sigma Aldrich (SaintLouis, MO). $\beta$-cyclodextrin, $p$-toluenesulfonyl chloride and Piroxicam were purchased from Alfa Aesar (Ward Hill, MA). Cation exchange resin beads Amberlist ${ }^{\circledR}$ IR 120, H were obtained from Acros Organics. Purified $18 \mathrm{M} \Omega$ ultrapure-water (Elga, Veolia) was used in the experiments. All other reagents and anhydrous solvents were commercially available and used without further purifications.

${ }^{1} \mathrm{H}$ NMR, which showed a shift referenced to the residual signal of non-fully deuterated NMR solvents, was recorded on a Bruker Advance DPX400 NMR spectrometer locked to the major signal of each NMR solvent. Samples were dissolved either in $\mathrm{D}_{2} \mathrm{O}$ or $d_{6}$-DMSO (Sigma Aldrich) at $25^{\circ} \mathrm{C}$. Scanning Electron Microscopy (SEM) images were obtained on a QuantaTM 250 FEG from FEI Company (Eidhoven, The Netherlands).

\section{1. 2. Biological reagents and equipment}

All media and supplements for cell culture were purchased from Sigma Aldrich (Saint Louis, MO). LPS from Escherichia coli (K12) was obtained from Invivogen (San Diego, CA).

Purified anti-mouse TNF- $\alpha$ antibody clone 1F3F3D4 and biotinylated anti-mouse TNF- $\alpha$ antibody clone XT3/XT22 for ELISA testing were purchased from eBioscience/thermoFischer Scientific (Waltham, MA). Horseradish Peroxidase Avidin (Avidin HRP) was from Jackson (West Grove, PA).

For the Flow Cytometry analysis, Fixable Viability Dye (FVD) eFluorTM 660 and Ki-67 monoclonal antibody clone SolA15 were from eBioscience and CD40 APC clone 3/23 was from BD Biosciences (San Jose, CA). Cells were analyzed on a FACScalibur from BD 
(Franklin Lake, NJ) using CellQuest Software (BD) for data acquisition and FlowJo Software (FlowJo Inc) for data analysis.

\section{2. Synthesis}

\section{2. 1. Synthesis of mono-6-deoxy-6-( $p$-toluensulfonyl)- $\beta$-cyclodextrin 1 (6-OTs- $\beta C D)$}

6-OTs- $\beta C D$ was synthetized accordingly to an organic solvent-free published methodology with minor modifications. ${ }^{36}$ In a round-bottom flask, dry $\beta$-cyclodextrin $(29.8 \mathrm{~g}, 26.3 \mathrm{mmol})$ was solubilized in $270 \mathrm{~mL}$ of milliQ-water and a $2.5 \mathrm{M}$ aqueous solution of $\mathrm{NaOH}(105 \mathrm{~mL})$ was added. Then, $7.6 \mathrm{~g}$ (39.9 mmol, $1.5 \mathrm{eq})$ of $p$-toluenesulfonyl chloride were added in little portions and the suspension was stirred for $1 \mathrm{~h}$ at room temperature. The residue was filtrated off and washed with water. To the filtrate solution (average $\mathrm{pH}=10$ ), cation exchange resin beads (Amberlist ${ }^{\circledR}$ IR $120, \mathrm{H}$ ) pre-activated with a $\mathrm{HCl} 6 \mathrm{M}$ aqueous solution, were added under stirring at room temperature. Reaching $\mathrm{pH}$ value of 2-3 led to the precipitation of the reaction product. The mixture was first filtered through sieve $(300 \mu \mathrm{m})$ to separate the resin beads from the expected 6-OTs- $\beta C D$. Then, the precipitated white powder was filtrated on a sinter glass. The paste obtained was finally washed with water and freeze-dried to give $\mathbf{1}$ as a white solid (yield: 23\%).

${ }^{1} \mathrm{H}$ NMR (DMSO-d $\left.d_{6}\right) \delta(\mathrm{ppm}) 7.76(\mathrm{~d}, 2 \mathrm{H}, \mathrm{Ph}), 7.44(\mathrm{~d}, 2 \mathrm{H}, \mathrm{Ph}), 5.88-5.63(\mathrm{~m}, 14 \mathrm{H}, \mathrm{OH} 2$ and

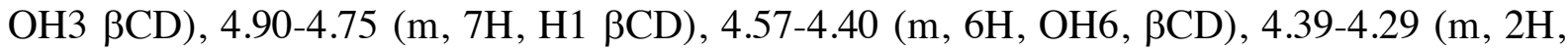
H6' $\beta \mathrm{CD}), 4.25-4.13(\mathrm{~m}, 1 \mathrm{H}, \mathrm{H} 5$ ' $\beta \mathrm{CD}), 3.74-3.50$ (m, 25H, H3, H5 et H6 $\beta \mathrm{CD}$ ), 3.48-3.19 (m, H2 and H4 $\beta C D$ overlap with water), 2.44 (s, 3H, Ph-CH3).

\section{2. 2. Synthesis of chitosan grafted with $\beta$-cyclodextrin 2 ( $\beta C D$-Chi)}


$\beta$-cyclodextrin-grafted chitosan 2 was synthesized following Yuan's method with minor modifications. ${ }^{41}$ Chitosan $(2.0 \mathrm{~g}, 12.4 \mathrm{mmol}$ repeating units) was first dissolved in $1 \%(\mathrm{v} / \mathrm{v})$ acetic acid $(160 \mathrm{~mL})$. A solution of 6-OTs- $\beta C D 1(7.0 \mathrm{~g}, 5.4 \mathrm{mmol}, 0.4 \mathrm{eq})$ in DMF $(80 \mathrm{~mL})$ was then added to the chitosan solution and the mixture was refluxed at $100^{\circ} \mathrm{C}$ for $16 \mathrm{~h}$. After a brief evaporation by distillation to decrease the volume of solvent, the solution was dialyzed through a membrane with a Molecular Weight Cut Off (MWCO) of 3,500 Da for 2 days against $0.1 \mathrm{M} \mathrm{NaCl}$ aqueous solution and then, against ultrapure water. The solution was finally freeze-dried to afford $2.7 \mathrm{~g}$ of 2 as a white solid (Degree of Substitution, DS=25\%, determined by $\left.{ }^{1} \mathrm{H} \mathrm{NMR}\right)$.

${ }^{1} \mathrm{H}$ NMR $\left(\mathrm{D}_{2} \mathrm{O}\right) \delta(\mathrm{ppm}) 7.60$ (d, Ph 6-OTs- $\left.\beta \mathrm{CD}\right), 7.28$ (d, Ph 6-OTs- $\left.\beta C D\right), 4.98$ (s, H1 $\beta \mathrm{CD}$ ), 3.90-3.42 (m, H2, H3, H4, H5, H6, $\beta C D$ and H1', H3', H4', H5', H6' chitosan), 2.89 (s, H2' chitosan), 2.32 (s, Ph-CH3 6-OTs- $\beta \mathrm{CD}$ ).

\section{3. General method for preparation of chitosan/alginate (Chi/Alg) Compact PolyElectrolyte Complexes}

Chitosan/alginate CoPECs were obtained as described in our previous work. ${ }^{31}$ Briefly, the alginate solution was obtained by dissolving sodium alginate in ultrapure water (1.25 $\mathrm{mg} / \mathrm{mL}$ ). The $\mathrm{pH}$ was then adjusted to 6.5 with an aqueous solution of acetic acid $0.1 \mathrm{M}$. Solid $\mathrm{NaBr}$ was added in little portions to reach $1 \mathrm{M}$ concentration.

The chitosan solution was obtained by suspending chitosan in ultrapure water $(1.25 \mathrm{mg} / \mathrm{mL})$ before adding $0.2 \%(\mathrm{v} / \mathrm{v})$ of acetic acid to reach complete dissolution. Then the $\mathrm{pH}$ was adjusted to 4.5 using a $\mathrm{NaOH} 6 \mathrm{M}$ aqueous solution. Solid $\mathrm{NaBr}$ was also added in little portions to reach a concentration of $1 \mathrm{M}$. 
The CoPECs were obtained by blending alginate and chitosan solutions in equal volumes. Perfect combination was performed by simultaneously pumping both solutions using a peristaltic pump (Ismatec IPC 9329, flow rate $=100 \mathrm{~mL} / \mathrm{min}$ ). The resultant mixture was stirred with a magnetic stir bar at $200 \mathrm{rpm}$ and the obtained suspension was then transferred into propylene centrifuge tubes and centrifuged at 9,400 g (Centrifuge Sigma $4 \mathrm{~K} 15 \mathrm{C}$ ) at $20^{\circ} \mathrm{C}$ for $15 \mathrm{~min}$. Finally, pre-compact complexes were transferred into thinwall polyallomer ultracentrifuge tubes (Beckman Coulter Inc.) with their supernatant and ultracentrifuged (Beckman Coulter Ultracentrifuge) at $308,000 \mathrm{~g}$ using a $90 \mathrm{Ti}$ rotor type at $23^{\circ} \mathrm{C}$ for $12 \mathrm{~h}$ to obtain CoPECs.

\section{4. Preparation of $\beta C D$-chitosan/alginate ( $\beta$ CD-Chi/Alg) Compact PolyElectrolyte}

\section{Complexes}

$\beta C D-C h i / A l g$ CoPECs were obtained following the same procedure described in the previous paragraph except that the quantity of chitosan was adjusted, due to the $\beta C D$ functionalization, in order to keep an equal amount of $-\mathrm{NH}_{3}{ }^{+}$on chitosan and of $\mathrm{COO}^{-}$on sodium alginate.

\section{5. Visualization of the microstructures by Scanning Electron Microscopy (SEM)}

After ultracentrifugation and washing, CoPECs were cut into slices and freeze-dried. The surface and the interior of the materials were then observed by SEM.

\section{6. Determination of the composition of $\beta C D$-Chi/Alg CoPEC}

\section{6. 1. Labeling of sodium alginate with rhodamine}


Sodium alginate was labeled with rhodamine B isothiocyanate following the procedure described by Ziv et al. with little modifications. ${ }^{42}$ An aqueous $2 \%$ (w/w) sodium alginate solution (300 $\mathrm{mg}, 1.5 \mathrm{mmol}$ ) was prepared and adjusted to $\mathrm{pH}$ 8. Then, rhodamine $\mathrm{B}$ isothiocyanate, mixed isomers $(20 \mathrm{mg}, 0.04 \mathrm{mmol}, 0.03 \mathrm{eq}$ ) in $8 \mathrm{~mL}$ DMSO was slowly added. The mixture was stirred at $40^{\circ} \mathrm{C}$ for $1 \mathrm{~h}$ before addition of $5.4 \mathrm{~g}$ of sodium chloride to stop the reaction. The product was dialyzed through a membrane with a MWCO of $12-14,000$ $\mathrm{Da}$ against $0.05 \mathrm{M} \mathrm{NaCl}$ and finally against ultrapure water until no significant fluorescence was detected in the dialysis medium. The product was then isolated by freeze-drying leading to $264 \mathrm{mg}$ of purple solid.

The substitution degree of the rhodamine-labeled alginate was determined by absorbance at $560 \mathrm{~nm}^{43}$ in $0.1 \mathrm{M} \mathrm{pH} 8$ phosphate buffer using a standard curve and was found to be of $0.7 \%$.

\section{6. 2. Preparation of the $\beta \mathrm{CD}-\mathrm{Chi} / \mathrm{Alg}$-rhodamine CoPEC}

As the molar mass of the sodium alginate was almost unmodified by the rhodamine labeling, the CoPEC was prepared following the same procedure and using the same polyelectrolytes proportions as for the unlabeled alginate until the ultracentrifugation step.

\section{6. 3. Estimation of the amount of alginate not included in the CoPEC}

The amount of alginate present in the supernatant before the ultracentrifugation step (to say, the amount of alginate which was not included in the final material) was determined by UVVis spectrophotometry at $560 \mathrm{~nm}$ using a standard curve obtained from alginate-rhodamine solutions in $0.1 \mathrm{M} \mathrm{pH} 8$ phosphate buffer. 


\section{7. Preparation of CoPECs microparticles}

CoPECs (Chi/Alg and $\beta C D-C h i / A l g)$ obtained by ultracentrifugation were washed during $24 \mathrm{~h}$ twice in Dulbecco's Phosphate-Buffered Saline (PBS, Sigma Aldrich, Saint Louis, MO), i. e. a solution of $136.9 \mathrm{mM} \mathrm{NaCl}, 1.5 \mathrm{mM} \mathrm{KH}_{2} \mathrm{PO}_{4}, 8.1 \mathrm{mM} \mathrm{Na} 2 \mathrm{HPO}_{4}$ and $2.7 \mathrm{mM} \mathrm{KCl}$, before the CoPECs pieces were freeze-dried. Successively they were grinded using a mortar and sieved (300 $\mu \mathrm{m}$ sieve from CISA) in order to obtain $\leq 300 \mu \mathrm{m}$ particles.

\section{8. Inclusion, extraction and quantification of Piroxicam in chitosan/alginate and $\beta C D$ - chitosan/alginate CoPECs}

$300 \mathrm{mg}$ of CoPECs microparticles were incubated in $90 \mathrm{~mL}$ of a $1 \mathrm{mg} / \mathrm{mL}$ Piroxicam solution in methanol for $72 \mathrm{~h}$ at $30^{\circ} \mathrm{C}$ and $90 \mathrm{rpm}$. Microparticles were collected by filtration, washed with a minimum of ultrapure water and dried at $37^{\circ} \mathrm{C}$ for $24 \mathrm{~h}$. Particles were then crushed and sieved at $300 \mu \mathrm{m}$ before extraction of the included Piroxicam was performed by incubating microparticles in $20 \mathrm{~mL}$ dichloromethane for $24 \mathrm{~h}$ at $30^{\circ} \mathrm{C}$ and $130 \mathrm{rpm}$. Microparticles were then separated by filtration, washed with dichloromethane and the filtrates were evaporated under reduced pressure to collect the extracted Piroxicam under its solid from. Extracted Piroxicam was dissolved in methanol, diluted in $0.1 \mathrm{M}$ aqueous $\mathrm{HCl}$ and was then quantified by UV-Vis spectrophotometry at $333 \mathrm{~nm}$ and by using a standard curve built from Piroxicam solutions in $0.1 \mathrm{M}$ aqueous $\mathrm{HCl}$.

\subsection{Evaluation of inflammation in an in vitro model}

\subsection{Cell culture}

RAW 264.7 mouse macrophages (ATCC@ TIB-71TM) were cultured in Dulbecco's Modified Eagle Medium High glucose (DMEM) containing stabilized glutamine, 
supplemented with 5\% (v/v) of fetal bovine serum (FBS), Penicillin (1000 U/mL) and Streptomycin $(100 \mu \mathrm{g} / \mathrm{mL})$ at $37^{\circ} \mathrm{C}$ in $5 \% \mathrm{CO} 2,95 \%$ humidity.

Cells were harvested at around $90 \%$ confluence using trypsin $(0.5 \mathrm{~g} / \mathrm{L})$-EDTA $(0.2 \mathrm{~g} / \mathrm{L})$ for 5 min at $37^{\circ} \mathrm{C}$ and re-suspended in culture medium to the desired dilution.

\section{9. 2. Cell incubation with CoPECs}

The incubation process was conducted over 3 days. The first day, 50, 000 cells/well were seeded with CoPECs microparticles concentrations ranging from 0.0677 to $2.2 \mathrm{mg} / \mathrm{mL}$ to a final culture medium volume of $100 \mu \mathrm{L}$ in 96 well plate flat bottom during 24 hours at $37^{\circ} \mathrm{C}$. On day 2, cells were stimulated with $50 \mathrm{ng} / \mathrm{mL}$ of LPS. On day 3, cells and supernatants were collected for subsequent analysis.

\section{9. 3. Assessment of NO production}

Concentrations of nitrogen dioxide in cell supernatants (representative of the nitric oxide produced by activated cells) were evaluated by Griess test $(n=3)$. Briefly, $60 \mu \mathrm{L}$ of Griess reagent (v/v mixture of $58.1 \mathrm{mM}$ p-aminobenzene sulfonamide in $30 \%$ acetic acid and 3.9 mM N-(1-naphtyl)ethylenediamine dihydrochloride in $60 \%$ acetic acid) were added to $40 \mu \mathrm{L}$ of supernatant and the absorbance at $543 \mathrm{~nm}$ was measured and compared to a sodium nitrite standard curve.

\section{9. 4. Assessment of TNF- $\alpha$ production}

TNF- $\alpha$ concentration in cell supernatants was evaluated by ELISA $(n=3)$ using commercially available reagents and following the manufacturer instructions.

Briefly, capture antibody was diluted to $1 \mu \mathrm{g} / \mathrm{mL}$ in a $0.05 \mathrm{M} \mathrm{pH} 9.6$ carbonate/bicarbonate buffer and coated 1 night at $4^{\circ} \mathrm{C}$ before blocking with PBS $0.05 \%$ Tween $201 \%$ BSA (1h, 
$\left.37^{\circ} \mathrm{C}\right)$. Samples were then diluted with PBS and incubated with capture antibody $\left(2 \mathrm{~h}, 37^{\circ} \mathrm{C}\right)$ before detection antibody diluted to $0.5 \mu \mathrm{g} / \mathrm{mL}$ in PBS $0.05 \%$ Tween $201 \%$ BSA was added $\left(1 \mathrm{~h}, 37^{\circ} \mathrm{C}\right)$. Avidin HRP was then introduced $\left(45 \mathrm{~min}, 37^{\circ} \mathrm{C}\right)$ and revelation was conducted by adding a solution of $1.25 \mathrm{mM}$ tetramethylbenzidine and $13.05 \mathrm{mM} \mathrm{H}_{2} \mathrm{O}_{2}$ in $0.1 \mathrm{M} \mathrm{pH} 5$ citrate buffer. Revelation was finally stopped by addition of $1 \mathrm{M} \mathrm{HCl}$ and absorbance was measured at $450 \mathrm{~nm}$.

\section{9. 5. Evaluation of the eventual trapping of LPS in CoPECs}

On day $1,1 \mathrm{mg} / \mathrm{mL} \beta \mathrm{CD}-\mathrm{Chi} / \mathrm{Alg} \mathrm{CoPEC}$ in the form of microparticles of diameter smaller than $300 \mu \mathrm{m}$ with $10 \mu \mathrm{L}$ of a $500 \mathrm{ng} / \mathrm{mL}$ LPS solution in culture medium were incubated in 96 well plate flat bottom during $24 \mathrm{~h}$ at $37^{\circ} \mathrm{C}$. In another plate, 50,000 cells/well were seeded and were also incubated during $24 \mathrm{~h}$ at $37^{\circ} \mathrm{C}$. On day 2 , supernatants of CoPEC in contact with LPS were collected, filtrated (FLOWNI CELL STAINERS, $70 \mu \mathrm{M}$ ) and placed on cells. On day 3, supernatants were collected and the NO content was assessed through a Griess test.

\section{9. 6. Evaluation of the eventual trapping of TNF- $\alpha$ in CoPECs}

On day $1,1 \mathrm{mg} / \mathrm{mL} \beta \mathrm{CD}-\mathrm{Chi} / \mathrm{Alg} \mathrm{CoPEC}$ in the form of microparticles of diameter smaller than $300 \mu \mathrm{m}$ in culture medium was placed in 96 well plate flat bottom during 24 hours at $37^{\circ} \mathrm{C}$. On day $2,10 \mu \mathrm{L}$ of a $20 \mathrm{ng} / \mathrm{mL}$ TNF- $\alpha$ solution were added. On day 3 , supernatants were collected and the TNF- $\alpha$ content in supernatants was then assessed by ELISA testing.

\section{9. 7. Flow Cytometry analysis}


PBS supplemented with 2\% FBS was used for washing and diluting the antibodies, FVD and the cells. Cells (105) were stained either with 1/2000 diluted Fixable Viability Dye eFluorTM 660 during $10-15 \mathrm{~min}$ at $37^{\circ} \mathrm{C}(\mathrm{n}=3)$ or $1 \mu \mathrm{g} / \mathrm{mL} \mathrm{CD} 40$ APC during $15 \mathrm{~min}$ at $4^{\circ} \mathrm{C}(\mathrm{n}=2)$. For Ki-67 staining, cells needed to be fixed with PFA $1 \%$ and permeabilized with cold pure acetone before addition of $0.25 \mu \mathrm{g} / \mathrm{mL} \mathrm{Ki}-67$ monoclonal antibody during $60 \mathrm{~min}$ at room temperature $(n=2)$. Cells were then analyzed on the cytometer.

\subsection{Statistical analysis}

The statistical significance was calculated using the GraphPad Prism 5.0 software by performing a multiple comparison RM two-way ANOVA with a Sidak's correction.

\section{ASSOCIATED CONTENT}

Supporting Information Available. Synthesis of $\beta C D$-alginate, assessment of IL-6 production from chitosan/ $\beta C D$-alginate CoPEC-treated macrophages, assessment of IL- 6 and TNF- $\alpha$ production by $\beta C D$-chitosan/ $\beta C D$-alginate CoPEC-treated macrophages, assessment of NO and TNF- $\alpha$ production by Piroxicam-containing $\beta C D$-chitosan/alginate CoPEC-treated and activated macrophages, assessment of NO production from chitosan, $\beta C D$-chitosan and sodium alginate-treated and activated macrophages.

This material is available free of charge via the Internet at http://pubs.acs.org.

\section{AUTHOR INFORMATION}

\section{Corresponding Authors}

* Dr De Giorgi Marcella 
Université de Strasbourg, CNRS, Laboratoire de Conception et Application de Molécules Bioactives UMR 7199, Faculté de Pharmacie, 74 route du Rhin, 67401 Illkirch Cedex, France Phone: +33 3688541 70; E-mail: degiorgi@unistra.fr

* Dr Frisch Benoît

Université de Strasbourg, CNRS, Laboratoire de Conception et Application de Molécules Bioactives UMR 7199, Faculté de Pharmacie, 74 route du Rhin, 67401 Illkirch Cedex, France Phone: +33 3688541 68; E-mail: frisch@unistra.fr

\section{ORCID}

Hardy Alexandre : https://orcid.org/0000-0003-2788-4697

Marcella De Giorgi : https://orcid.org/0000-0003-1035-8519

Benoît Frisch: https://orcid.org/0000-0002-8378-2508

Philippe Lavalle : https://orcid.org/0000-0001-8798-912X

Pierre Schaaf : https://orcid.org/ 0000-0001-7423-5492

\section{Author Contributions}

The manuscript was written through contributions of all authors. All authors have given approval to the final version of the manuscript.

\section{Funding Sources}

Author A. Hardy gratefully acknowledges financial support from Ministère de l'Enseignement Supérieur et de la Recherche; authors C. Seguin, A. Brion, S. Fournel, L. Bourel-Bonnet, B. Frisch and M. De Giorgi acknowledge Université de Strasbourg, and Centre National de la Recherche Scientifique (C.N.R.S.). Authors P. Lavalle and P. Schaaf 
thank financial support from Institut National de la Santé et de la Recherche Médicale (I.N.S.E.R.M.)

\section{Notes}

The authors declare no competing financial interest.

\section{ACKNOWLEDGMENT}

We acknowledge Eric Mathieu and Joseph Hemmerlé for their support for MEB experiences.

\section{ABBREVIATIONS}

Avidin HRP, Horseradish Peroxidase Avidin; CD, cyclodextrin; COPEC, compact polyelectrolyte complexes; DAMP, damage-associated molecular pattern; DS, substitution degree; IL-6, interleukin 6; LPS, lipopolysaccharide; NO, nitric oxide; PAA, poly(acrylic acid); PAH, poly(allylamine hydrochloride); PAMP, pathogen-associated molecular pattern; PDADMA, poly(diallyldimethylammonium); PMMA, poly(methyl methacrylate); PSS, poly(styrene sulfonate); TNF- $\alpha$, tumor necrosis factor alpha.

\section{REFERENCES}

1. Patel, N. R.; Gohil, P. P., A Review on Biomaterials: Scope, Applications \& Human Anatomy Significance. Int. J. Adv. Res. Technol. 2012, 2 (4), 91-101.

2. $\quad$ Merrell, J. G.; McLaughlin, S. W.; Tie, L.; Laurencin, C. T.; Chen, A. F.; Nair, L. S., Curcumin-Loaded Poly(Epsilon-Caprolactone) Nanofibres: Diabetic Wound Dressing with Anti-Oxidant and Anti-Inflammatory Properties. Clin. Ex. Pharmacol. Physiol. 2009, 36 (12), $1149-1156$.

3. Mendez, J. A.; Fernandez, M.; Gonzalez-Corchon, A.; Salvado, M.; Collia, F.; de Pedro, J. A.; Levenfeld, B. L.; Lopez-Bravo, A.; Vazquez, B.; San Roman, J., Injectable SelfCuring Bioactive Acrylic-Glass Composites Charged with Specific AntiInflammatory/Analgesic Agent. Biomaterials 2004, 25 (12), 2381-2392.

4. Ito, T.; Fraser, I. P.; Yeo, Y.; Highley, C. B.; Bellas, E.; Kohane, D. S., AntiInflammatory Function of An In Situ Cross-Linkable Conjugate Hydrogel of Hyaluronic Acid and Dexamethasone. Biomaterials 2007, 28 (10), 1778-1786.

5. Webber, M. J.; Matson, J. B.; Tamboli, V. K.; Stupp, S. I., Controlled Release of Dexamethasone from Peptide Nanofiber Gels to Modulate Inflammatory Response. Biomaterials 2012, 33 (28), 6823-6832. 
6. Lee, C. H.; Lo, L. W.; Mou, C. Y.; Yang, C. S., Synthesis and Characterization of Positive-Charge Functionalized Mesoporous Silica Nanoparticles for Oral Drug Delivery of an Anti-Inflammatory Drug. Adv. Funct. Mater. 2008, 18 (20), 3283-3292.

7. Wong, K. K. Y.; Cheung, S. O. F.; Huang, L. M.; Niu, J.; Tao, C.; Ho, C. M.; Che, C. M.; Tam, P. K. H., Further Evidence of the Anti-inflammatory Effects of Silver Nanoparticles. ChemMedChem 2009, 4 (7), 1129-1135.

8. Davida, L.; Moldovana, B.; Vulcub, A.; Olenicb, L.; Perde-Schreplerc, M.; FischerFodorc, E.; Floread, A.; Crisane, M.; Chioreanf, I.; Clichicig, S.; Filipg, G. A., Green Synthesis, Characterization and Anti-Inflammatory Activity of Silver Nanoparticles Using European Black Elderberry Fruits Extract. Colloids Surf. B 2014, 122, 767-777.

9. Moldovan, B.; David, L.; Vulcu, A.; Olenic, L.; Perde-Schrepler, M.; Fischer-Fodor, E.; Baldea, I.; Clichici, S.; Filip, G. A., In Vitro and In Vivo Anti-Inflammatory Properties of Green Synthesized Silver Nanoparticles Using Viburnum Opulus L. Fruits Extract. Mater. Sci.Eng., C 2017, 79, 720-727.

10. Hirst, S. M.; Karakoti, A. S.; Tyler, R. D.; Sriranganathan, N.; Seal, S.; Reilly, C. M., Anti-Inflammatory Properties of Cerium Oxide Nanoparticles. Small 2009, 5 (24), 2848-2856. 11. Xu, M. X.; Zhu, Y. F.; Chang, H. F.; Liang, Y., Nanoceria Restrains Pm2.5-Induced Metabolic Disorder and Hypothalamus Inflammation by Inhibition of Astrocytes Activation Related Nf-Kappab Pathway in Nrf2 Deficient Mice. Free Radic. Biol. Med. 2016, 99, 259272.

12. Wang, H.; Zhu, H.; Fu, W.; Zhang, Y.; Xu, B.; Gao, F.; Cao, Z.; Liu, W., A High Strength Self-Healable Antibacterial and Anti-Inflammatory Supramolecular Polymer Hydrogel. Macromol. Rapid Commun. 2017, 38 (9), doi:10.1002/marc.201600695.

13. Isa, I. L. M.; Srivastava, A.; Tiernan, D.; Owens, P.; Rooney, P.; Dockery, P.; Pandit, A., Hyaluronic Acid Based Hydrogels Attenuate Inflammatory Receptors and Neurotrophins in Interleukin-1\# Induced Inflammation Model of Nucleus Pulposus Cells. Biomacromolecules 2015, 16 (6), 1714-1725.

14. Raafat, D.; Sahl, H. G., Chitosan and its Antimicrobial Potential-A Critical Literature Survey. Microb. Biotechnol. 2009, 2 (2), 186-201.

15. Nalamothu, N.; Potluri, A.; Muppalla, M., B., Review on Marine Alginates and Its Applications. Indo Am. J. Pharm. Res. 2014, 4 (10), 4006-4015.

16. Wang, L. H.; Khor, E.; Wee, A.; Lim, L. Y., Chitosan-Alginate PEC Membrane as A Wound Dressing: Assessment of Incisional Wound Healing. J. Biomed. Mater. Res. 2002, 63 (5), 610-618.

17. Costa, R. R.; Costa, A. M. S.; Caridade, S. G.; Mano, J. F., Compact Saloplastic Membranes of Natural Polysaccharides for Soft Tissue Engineering. Chem. Mater. 2015, 27 (21), 7490-7502.

18. Pfister, L. A.; Papaloizos, M.; Merkle, H. P.; Gander, B., Hydrogel Nerve Conduits Produced from Alginate/Chitosan Complexes. J. Biomed. Mater. Res., A 2007, 80 (4), 932937.

19. Gazori, T.; Khoshayand, M. R.; Azizi, E.; Yazdizade, P.; Nomanie, A.; Haririan, I., Evaluation of Alginate/Chitosan Nanoparticles As Antisense Delivery Vector: Formulation, Optimization And In Vitro Characterization. Carbohydr. Polym. 2009, 77 (3), 599-606.

20. Nagarwal, R. C.; Kumar, R.; Pandit, J. K., Chitosan Coated Sodium AlginateChitosan Nanoparticles Loaded with 5-Fu for Ocular Delivery: In Vitro Characterization And In Vivo Study in Rabbit Eye. Eur. J. Pharm. Sci. 2012, 47 (4), 678-685.

21. Sarmento, B.; Ribeiro, A.; Veiga, F.; Sampaio, P.; Neufeld, R.; Ferreira, D., Alginate/Chitosan Nanoparticles are Effective for Oral Insulin Delivery. Pharm. Res. 2007, 24 (12), 2198-2206. 
22. Acosta, N.; Aranaz, I.; Peniche, C.; Heras, A., Tramadol Release from a Delivery System Based on Alginate-Chitosan Microcapsules. Macromol. Biosci. 2003, 3 (10), 546-551. 23. Natrajan, D.; Srinivasan, S.; Sundar, K.; Ravindran, A., Formulation of Essential OilLoaded Chitosan-Alginate Nanocapsules. J. Food Drug Anal. 2015, 23 (3), 560-568.

24. Tigli, R. S.; Gumusderelioglu, M., Evaluation of Alginate-Chitosan Semi INPs As Cartilage Scaffolds. J. Mater. Sci. Mater. Med. 2009, 20 (3), 699-709.

25. Shao, X. X.; Hunter, C. J., Developing an Alginate/Chitosan Hybrid Fiber Scaffold for Annulus Fibrosus Cells. J. Biomed. Mater. Res., A 2007, 82 (3), 701-710.

26. Hariri, H. H.; Schlenoff, J. B., Saloplastic Macroporous Polyelectrolyte Complexes: Cartilage Mimics. Macromolecules 2010, 43 (20), 8656-8663.

27. Porcel, C. H.; Schlenoff, J. B., Compact Polyelectrolyte Complexes: "Saloplastic" Candidates for Biomaterials. Biomacromolecules 2009, 10 (11), 2968-2975.

28. Reisch, A.; Roger, E.; Phoeung, T.; Antheaume, C.; Orthlieb, C.; Boulmedais, F.; Lavalle, P.; Schlenoff, J. B.; Frisch, B.; Schaaf, P., On the Benefits of Rubbing Salt in the Cut: Self-Healing of Saloplastic PAA/PAH Compact Polyelectrolyte Complexes. Adv. Mater. 2014, 26 (16), 2547-2551.

29. Reisch, A.; Tirado, P.; Roger, E.; Boulmedais, F.; Collin, D.; Voegel, J.-C.; Frisch, B.; Schaaf, P.; Schlenoff, J., Compact Saloplastic Poly(Acrylic Acid)/Poly(Allylamine) Complexes: Kinetic Control Over Composition, Microstructure, and Mechanical Properties. Adv. Funct. Mater. 2013, 23 (6), 673-682.

30. Tirado, P.; Reisch, A.; Roger, E.; Boulmedais, F.; Jierry, L.; Lavalle, P.; Voegel, J.-C.; Schaaf, P.; Schlenoff, J.; Frisch, B., Catalytic Saloplastics: Alkaline Phosphatase Immobilized and Stabilized in Compacted Polyelectrolyte Complexes. Adv. Funct. Mater. 2013, 23 (38), 4785-4792.

31. Phoeung, T.; Spanedda, M. V.; Roger, E.; Heurtault, B.; Foumel, S.; Reisch, A.; Mutschler, A.; Perrin-Schmitt, F.; Hemmerle, J.; Collin, D.; Rawiso, M.; Boulmedais, F.; Schaaf, P.; Lavalle, P.; Frisch, B., Alginate/Chitosan Compact Polyelectrolyte Complexes (CoPEC): A Cell and Bacterial Repellent Material. Chem. Mater. 2017, 29 (24), 1041810425.

32. Crini, G., Review: A History of Cyclodextrins. Chem. Rev. 2014, 114 (21), 1094010975.

33. Kurkov, S. V.; Loftsson, T., Cyclodextrins. Int. J. Pharm. 2013, 453 (1), 167-180.

34. Arun, R., Cyclodextrins as Drug Carrier Molecule: A Review. Sci. Pharm. 2008, 76 (4), 567-598.

35. Khan, A. R.; Forgo, P.; Stine, K. J.; D'Souza, V. T., Methods for Selective Modifications of Cyclodextrins. Chem. Rev. 1998, 98 (5), 1977-1996.

36. Tripodo, G.; Wischke, C.; Neffe, A. T.; Lendlein, A., Efficient Synthesis of Pure Monotosylated Beta-Cyclodextrin And its Dimers. Carbohydr. Res. 2013, 381, 59-63.

37. Gonil, P.; Sajomsang, W.; Ruktanonchai, U. R.; Pimpha, N.; Sramala, I.; Nuchuchua, O.; Saesoo, S.; Chaleawlert-umpon, S.; Puttipipatkhachorn, S., Novel Quaternized Chitosan Containing beta-Cyclodextrin Moiety: Synthesis, Characterization And Antimicrobial Activity. Carbohydr. Polym. 2011, 83 (2), 905-913.

38. Chiong, H. S.; Yong, Y. K.; Ahmad, Z.; Sulaiman, M. R.; Zakaria, Z. A.; Yuen, K. H.; Hakim, M. N., Cytoprotective And Enhanced Anti-Inflammatory Activities of Liposomal Piroxicam Formulation in Lipopolysaccharide-Stimulated Raw 264.7 Macrophages. Int. J. Nanomedicine

2013, $8,1245-1255$.

39. Yoon, H. J.; Moon, M. E.; Park, H. S.; Im, S. Y.; Kim, Y. H., Chitosan Oligosaccharide (COS) Inhibits LPS-Induced Inflammatory Effects In Raw 264.7 Macrophage Cells. Biochem. Biophys. Res. Commun. 2007, 358 (3), 954-959. 
40. Zhu, J.; Zhang, Y.; Wu, G.; Xiao, Z.; Zhou, H.; Yu, X., Inhibitory Effects of Oligochitosan on TNF-alpha, Il-1beta And Nitric Oxide Production In LipopolysaccharideInduced Raw264.7 Cells. Mol. Med. Rep. 2015, 11 (1), 729-733.

41. Yuan, Z.; Ye, Y.; Gao, F.; Yuan, H.; Lan, M.; Lou, K.; Wang, W., Chitosan-GraftBeta-Cyclodextrin Nanoparticles as A Carrier for Controlled Drug Release. Int. J. Pharm. 2013, 446 (1-2), 191-198.

42. Ziv, K.; Nuhn, H.; Ben-Haim, Y.; Sasportas, L. S.; Kempen, P. J.; Niedringhaus, T. P.; Hrynyk, M.; Sinclair, R.; Barron, A. E.; Gambhir, S. S., A Tunable Silkealginate Hydrogel Scaffold for Stem Cell Culture And Transplantation. Biomaterials 2014, 35 (12), 3736-3743. 43. Mladenovska, K.; Cruaud, O.; Richomme, P.; Belamie, E.; Raicki, R. S.; VenierJulienne, M. C.; Popovski, E.; Benoit, J. P.; Goracinova, K., 5-ASA Loaded Chitosan-CaAlginate Microparticles: Preparation And Physicochemical Characterization. Int. J. Pharm. 2007, 345 (1-2), 59-69.

\section{TOC Graphic}

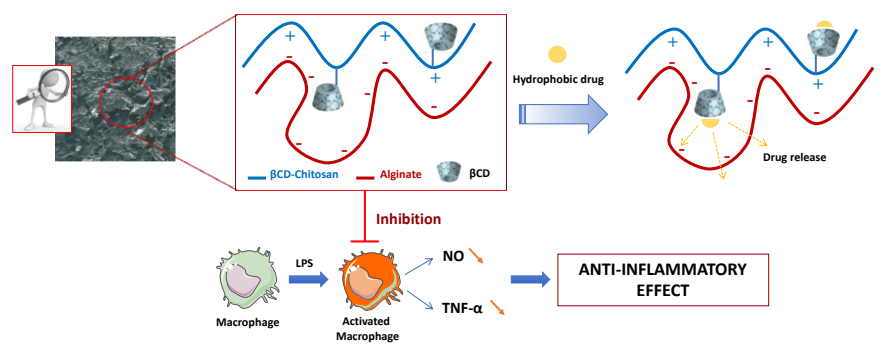

